\title{
Gebildet Wie ist Bildung
}

\section{möglich?}

W $\begin{aligned} & \text { as Bildung in der Welt und im Lebenslauf bedeutet, das } \\ & \text { sagen die Historiker und Soziologen und die großen }\end{aligned}$ Romane. Was sie sein soll, das beschwören in immer neuen Bildern des Wahren, Guten und Schönen, der besseren Welten und tugendhafter Menschen die Philosophen. Offen ist nur die wesentliche Frage: »Wie ist Bildung möglich?«, zumal die Form von Bildung und der Gebildeten, von der die Philosophen reden. Nach Sokrates gibt es wenig positive Beispiele, schon gar nicht im Alltag und in der Geschichte. Dort findet man das Versagen gebildeter Eliten, deutsche semantische Sonderwege, die Untiefen der Innerlichkeit, feine Unterschiede und immer neue Katastrophen. Geht es besser? Gelegentlich ist man dann versucht, die Pädagogen zu fragen. Aber die fordern Reformen, wenn man sie auf ihre Leistungen anspricht, und erklären Bildung ansonsten zur Leistung des Subjekts. Mit dem Plädoyer für Selbstbildung verlagern sie aber nur die Verantwortung und die Probleme dorthin, wo die offene Frage ihren Ursprung hat, in einen Alltag, der primär die Differenz zu dem markiert, was die Philosophen wollen. Sollte die Frage so schwierig sein, dass wir sogar den Angeboten der Neurowissenschaften nähertreten müssen? Dann haben wir der Bildung zumindest den Geist ausgetrieben. 